\title{
Mitigation of Sn Whisker Growth by Small Bi Additions
}

\author{
JUNG-LAE JO ${ }^{1,3}$ SHIJO NAGAO ${ }^{1}$ KYOKO HAMASAKI, ${ }^{1}$ \\ MASANOBU TSUJIMOTO, ${ }^{2}$ TOHRU SUGAHARA, ${ }^{1}$ \\ and KATSUAKI SUGANUMA ${ }^{1}$
}

1.-Institute of Scientific and Industrial Research, Osaka University, 8-1 Mihogaoka, Ibaraki, Osaka 567-0047, Japan. 2.-R\&D Division, C. Uyemura \& Co., Ltd., 1-5-1 Deguchi, Hirakata, Osaka 573-0065, Japan. 3.—e-mail: jljo@eco.sanken.osaka-u.ac.jp

\begin{abstract}
In this study, the morphological development of electroplated matte Sn and Sn- $x \operatorname{Bi}(x=0.5$ wt. $\%, 1.0$ wt.\%, 2.0 wt.\%) film surfaces was investigated under diverse testing conditions: 1-year room-temperature storage, high temperature and humidity (HTH), mechanical loading by indentation, and thermal cycling. These small Bi additions prevented Sn whisker formation; no whisker growth was observed on any $\mathrm{Sn}-x \mathrm{Bi}$ surface during either the room-temperature storage or HTH testing. In the indentation loading and thermal cycling tests, short $(<5 \mu \mathrm{m})$ surface extrusions were occasionally observed, but only on $x=0.5$ wt.\% and 1.0 wt.\% plated samples. In all test cases, Sn-2Bi plated samples exhibited excellent whisker mitigation, while pure Sn samples always generated many whiskers on the surface. We confirmed that the addition of $\mathrm{Bi}$ into $\mathrm{Sn}$ refined the grain size of the as-plated films and altered the columnar structure to form equiaxed grains. The storage conditions allowed the formation of intermetallic compounds between the plated layer and the substrate regardless of the $\mathrm{Bi}$ addition. However, the growth patterns became more uniform with increasing amounts of Bi. These microstructural improvements with $\mathrm{Bi}$ addition effectively released the internal stress from Sn plating, thus mitigating whisker formation on the surface under various environments.
\end{abstract}

Key words: Sn whisker, Sn-Bi electroplating, Sn whisker mitigation, grain refinement, intermetallic compound

\section{INTRODUCTION}

Eliminating use of $\mathrm{Pb}$ in electronic device packaging has been actively pursued for the last decade due to the Restriction of Hazardous Substances directive for electronic equipment. ${ }^{1,2}$ Electroplating in packaging is also expected to be $\mathrm{Pb}$ free, even though $\mathrm{Sn}-\mathrm{Pb}$ alloys have ideal properties for soldering: excellent wettability, reasonably low melting points, and superior tolerance against $\mathrm{Sn}$ whisker formation under various environments. Sn whiskers can grow up to a few millimeters under usual operating conditions and may cause shortcircuit failures and malfunctions in electronic components; For example, a whisker of length more than $100 \mu \mathrm{m}$ can easily form a bridge in fine-pitch

(Received April 15, 2013; accepted July 18, 2013;

published online September 4, 2013) wiring and electrode systems, which are becoming ever smaller with the trend towards device miniaturization. ${ }^{3,4}$ Various methods for mitigating $\mathrm{Sn}$ whisker formation have hence been proposed; For instance, heat treatment at $150^{\circ} \mathrm{C}$ for more than 30 min typically releases the residual stress in a material. Annealing creates a uniform intermetallic compound (IMC) layer at the interface between the $\mathrm{Cu}$ substrate and the plated layer and prevents further IMC growth along the grain boundaries by reducing the $\mathrm{Cu}$ diffusion rate. ${ }^{5-7}$ The grain sizes in both the electroplated films and the interface IMC $\left(\mathrm{Cu}_{6} \mathrm{Sn}_{5}\right)$ are related to the plating thickness; ${ }^{8}$ thick plating is generally effective for relieving compressive stress. It has been observed that, the thicker the plating, the lower the whisker density. 9,10

Recently, we revealed a whisker mitigation mechanism by adding a trace amount of $\mathrm{Pb}$, which effectively suppressed whisker growth on Sn plating 
for over 1 year of ambient storage. ${ }^{11}$ Addition of even 1 wt.\% Pb effectively suppressed Sn whiskers by inhibiting grain boundary (GB) IMC growth without altering the columnar grain structure.

In this study, we propose the addition of a small amount of $\mathrm{Bi}$, instead of $\mathrm{Pb}$, to avoid whisker growth on Sn electroplated surfaces. ${ }^{11}$ When alloying $\mathrm{Bi}$ with Sn, the columnar grains of the films changed to equiaxed grains. ${ }^{12}$ Under thermal cycling, the measured stress of $7.5-\mu \mathrm{m}$ Sn with $2.5 \mathrm{wt} . \%$ to 10 wt.\% Bi content showed relaxation similar to that of $\mathrm{Sn}-\mathrm{Pb}$ plated samples. Here, we investigate the addition of smaller amounts of $\mathrm{Bi}$, i.e., Sn- $x \mathrm{Bi}$ $(x \leq 2$ wt.\%) electroplating, and demonstrate whisker mitigation under various environmental

Table I. Substrate types, plating thickness, and amount of $\mathrm{Bi}$ addition

\begin{tabular}{|c|c|c|}
\hline Substrate & Copper & 42 Alloy \\
\hline $\begin{array}{l}\text { Plating thickness } \\
\text { wt. } \% \text { of } \mathrm{Bi}\end{array}$ & $\begin{array}{c}5 \mu \mathrm{m} \\
0,0.5,1,2\end{array}$ & $\begin{array}{c}5 \mu \mathrm{m} \\
0,0.5,1,2\end{array}$ \\
\hline
\end{tabular}

conditions. We also show that $\mathrm{Bi}$ addition achieves equiaxed grain structures in thinner $(5 \mu \mathrm{m})$ as-plated Sn films as well as finer grain sizes. All Bi-doped samples exhibited excellent whisker mitigation in our tests: long-term ambient storage, high temperature and humidity (HTH), mechanical loading, and thermal cycling. The excellent results of these environmental tests prove that small $\mathrm{Bi}$ additions achieve $\mathrm{Pb}$-free whisker mitigation of $\mathrm{Sn}$ electroplating under operating conditions relevant to electronic devices.

\section{EXPERIMENTAL PROCEDURES}

Matte $\mathrm{Sn}$ and $\mathrm{Sn}-x \mathrm{Bi}(x=0.5 \mathrm{wt} . \%, 1.0 \mathrm{wt} . \%$, 2.0 wt.\%) films were electroplated on $\mathrm{Cu}$ and 42 alloy (Fe-Ni) lead frame sheets for quad flat packaging using an electric current density of $2 \mathrm{~A} / \mathrm{dm}^{2}$. Electroplating was performed in a $3 \mathrm{~L}$ bath solution with $\mathrm{pH}$ of 1 at $25^{\circ} \mathrm{C}$ for $310 \mathrm{~s}$. After electroplating, all samples were cleaned with distilled water, then dried for $20 \mathrm{~s}$ using a dry air gun. The film thickness was $\sim 5 \mu \mathrm{m}$ for all samples. Table I presents the details of the electroplating conditions. All samples were characterized by four tests: ambient storage

Table II. Testing conditions and substrate materials

\begin{tabular}{|c|c|c|c|}
\hline Test Type & Period and Cycles & Variables & Substrate \\
\hline Room-temperature storage & 1 year & $25 \pm 5^{\circ} \mathrm{C} / 25 \%$ & $\mathrm{Cu}$ \\
\hline High humidity/temperature & $1000 \mathrm{~h}$ & $85^{\circ} \mathrm{C} / 85 \% \mathrm{RH}$ & $\mathrm{Cu}$ \\
\hline Indentation loading & Up to 3 days & $300 \mathrm{~g}(r=100 \mu \mathrm{m}$ ball $)$ & $\mathrm{Cu}$ \\
\hline Thermal cycling & Up to 100 cycles & $-20^{\circ} \mathrm{C}$ to $80^{\circ} \mathrm{C}$ & 42 alloy \\
\hline
\end{tabular}

(a)

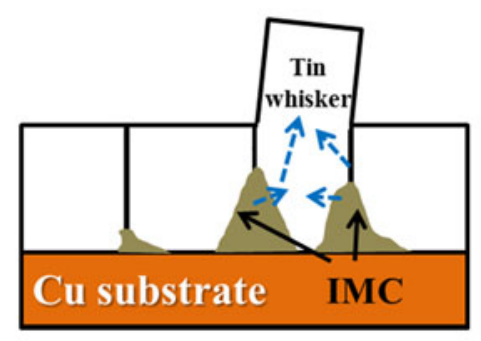

(c)

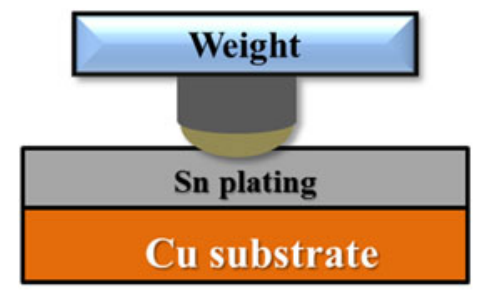

(b)

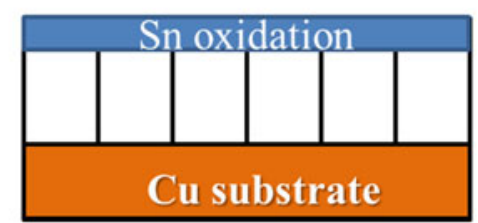

(d)

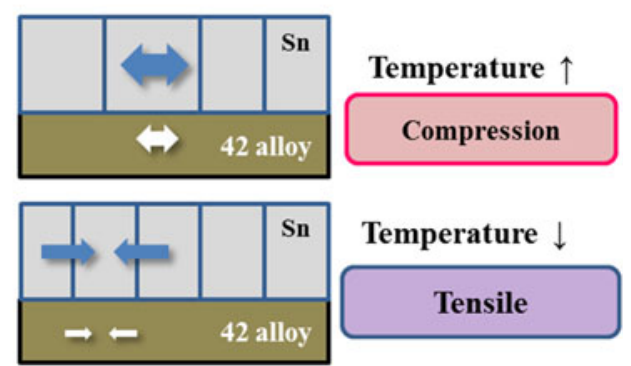

Fig. 1. Schematic diagrams of (a) ambient storage test, (b) high-humidity/temperature test, (c) loading test, and (d) thermal cycling test. 
for 1 year, HTH, mechanical loading by ball indentation, and thermal cycling. We prepared 42 alloy lead frame sheets for thermal cycle testing because the coefficient of thermal expansion (CTE) mismatch is large for the combination of Sn plating and this substrate, allowing accelerated thermal stress cycling. In addition, the effect of IMC growth during thermal cycling can be eliminated because of the negligible diffusion of $\mathrm{Fe} / \mathrm{Ni}$ into the $\mathrm{Sn}$ plating. Details of the testing conditions are presented in Table II. One-year ambient storage tests at room temperature were conducted for all samples. A custom indentation tool was used for the loading test with a $\mathrm{ZrO}_{2}$ ball of $300 \mathrm{~g}$. Thermal cycling tests were performed up to 100 cycles in a testing chamber (UTC200A; Ampere. Co. Ltd., Japan). HTH tests were conducted for $1000 \mathrm{~h}$ using a high-humidity, high-temperature chamber (SH-221; Espec, Japan). Figure 1 shows schematic diagrams of all the tests performed in this study.

The growth behavior of Sn whiskers and the evolution of the surface microstructure were observed using field-emission scanning electron microscopy (FE-SEM 2100, JEOL, and SU0820, Hitachi, Japan). A focused ion beam (FIB) microscope (FB-2100; Hitachi, Japan) was used to fabricate cross-sectional samples of the coatings, whiskers, and hillocks as well as to perform imaging. The grain sizes of Sn and Sn-xBi films were determined at a depth of $1 \mu \mathrm{m}$ from the upper surface using FIB etching and microscopy.

\section{RESULTS AND DISCUSSION}

\section{Surface Evolution of Sn- $x$ Bi Electroplated Films During Environmental Testing}

Figure 2 shows the results of the ambient storage tests (a) as-plated and (b) after 1 year. All prepared samples appear to have flat surfaces without whiskers or cracks, but the morphologies of the topmost surfaces are different according to the amount of $\mathrm{Bi}$ addition; the size of surface grains decreased with increasing Bi content in Sn (Fig. 2a). Thus, small Bi addition results in Sn grain refinement. A similar effect caused by alloying $\mathrm{Sn}-\mathrm{Pb}$ has been reported. ${ }^{11,13,14}$ As shown in Fig. $2 \mathrm{~b}$, Sn whiskers can be observed only on the pure Sn surface during 1-year ambient storage. Usually, Sn whiskers grow on a pure Sn surface within $24 \mathrm{~h}$ of electroplating. ${ }^{11}$ However, in contrast, no whiskers were observed on the $\mathrm{Sn}-x \mathrm{Bi}$ surfaces, regardless of the $\mathrm{Bi}$ content, while only hillocks were observed on the $\mathrm{Sn}-0.5 \mathrm{Bi}$ and $\mathrm{Sn}-1 \mathrm{Bi}$ surfaces. These results are similar to our previous results, where we attempted to eliminate Sn whiskers during 1-year ambient storage by small $\mathrm{Pb}$ addition to Sn. ${ }^{11}$ The present results confirm that addition of a trace amount of $\mathrm{Bi}$, namely $0.5 \mathrm{wt} . \%$ in a $5-\mu \mathrm{m}$ plated film, is sufficient to mitigate Sn whisker formation for up to 1 year of ambient-temperature storage.

Figure 3 shows that the HTH test results exhibit tendencies similar to the ambient storage results.

The dotted red circle in Fig. 3a indicates a Sn whisker grown on a pure Sn surface during $1000 \mathrm{~h}$ of HTH storage. Such whiskers can develop on pure Sn surface under high-humidity conditions. ${ }^{15-17}$ Oxidation and corrosion of the metal induce volume expansion in the Sn plating layer during highhumidity storage, and whiskers grow to relieve the accumulated compressive stress resulting from this expansion. ${ }^{16}$ In our case, with $\mathrm{Bi}$ addition, almost no morphological changes were observed on any $\mathrm{Sn}-x \mathrm{Bi}$ surface, as shown in Fig. 3b-d. Thus, as little as 0.5 wt.\% Bi addition can effectively prevent $\mathrm{Sn}$ whisker formation under high-temperature and high-humidity storage.

Ball indentation tests were performed to investigate whisker growth driven by external mechanical stress. Figure 4 illustrates the surface evolution of pure $\mathrm{Sn}$ surface and $\mathrm{Sn}-x \mathrm{Bi}$ plating after $72 \mathrm{~h}$ of mechanical loading. The indentation impression is shown in the lower-magnification microscope image (Fig. 4a-1). After $24 \mathrm{~h}$ of loading, Sn whiskers were induced on the pure Sn surface, while no whiskers were formed near the impression edge on the $\mathrm{Sn}-x \mathrm{Bi}$

\section{(a)}
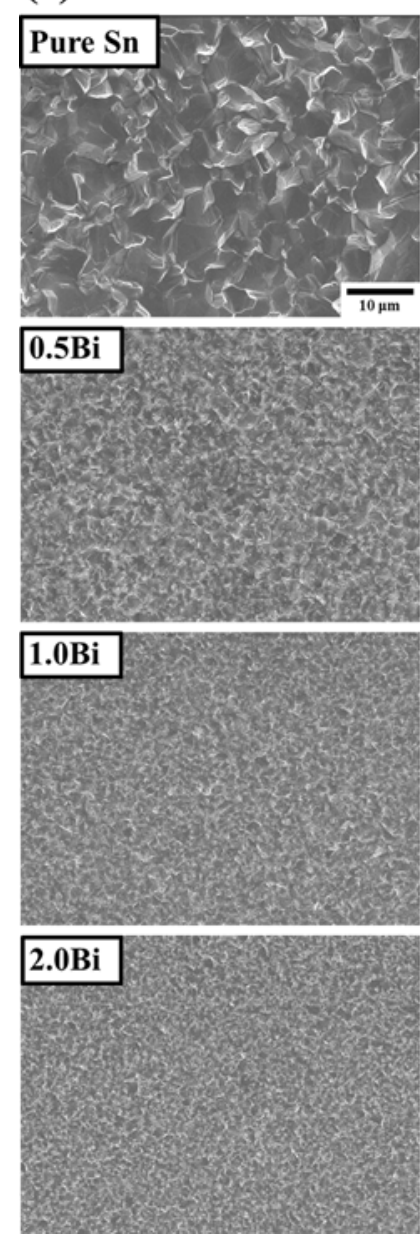

Fig. 2. Surface evolution of matte $\mathrm{Sn}$ and $\mathrm{Sn}-x \mathrm{Bi}$ : (a) as-plated and

(b) after 1-year ambient storage.

\section{(b)}
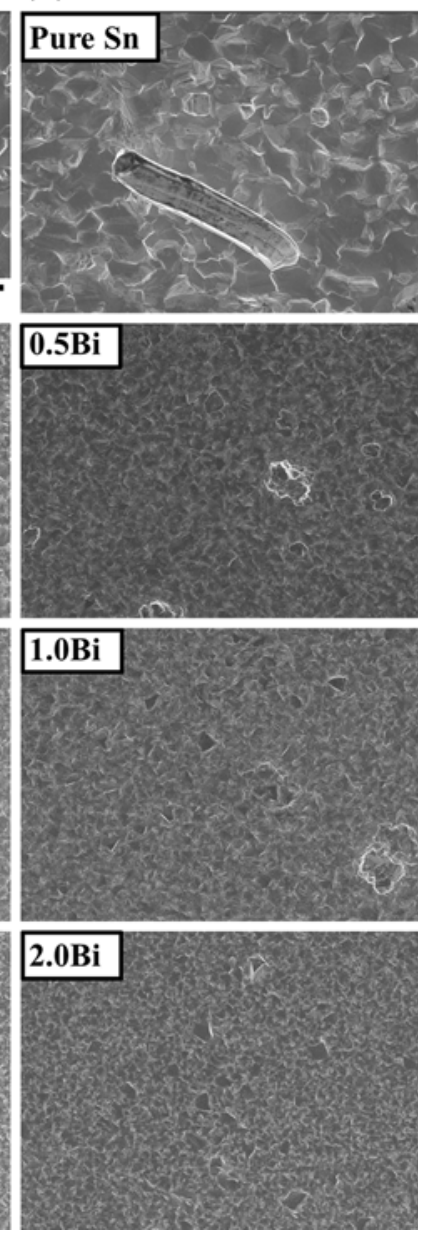
surfaces regardless of the Bi content. A Sn whisker $\sim 35 \mu \mathrm{m}$ in length grew near the indented area after $72 \mathrm{~h}$ of loading on the pure Sn surface, as shown in Fig. 4a. In addition, the lengths of the Sn whiskers on the pure Sn surface were considerably shorter further away from the indentation, as shown by the dotted red circles in Fig. 4a. On the Sn-0.5Bi and Sn-1Bi surfaces in Fig. $4 \mathrm{~b}$ and c, however, many short extrusions such as nodules and hillocks grew in the vicinity of the indentation perimeter, although their lengths were $<5 \mu \mathrm{m}$ after $72 \mathrm{~h}$ of loading. On the Sn-2Bi surface, no whiskers, but small hillocks, were observed near the indentation (Fig. 4d). These results indicate that $\mathrm{Bi}$ addition, particularly at 2 wt.\%, is efficient for whisker mitigation even under directly applied external mechanical stress.

Thermal cycling tests were performed up to 100 cycles with pure Sn and Sn- $x \mathrm{Bi}$ surfaces on 42 alloy substrates. The CTE mismatch between the plated layer and the substrate repeatedly induced compressive and tensile stress in the plating layer during thermal cycling. Figure 5a shows a typical whisker developed on a pure Sn surface during thermal cycling, which was often accompanied by large grooves around the whisker root (marked by yellow dotted arrows). Many GB cracks were observed, particularly on the pure Sn surface (indicated by red arrows). This GB cracking and grooves were due to surface oxidation, ${ }^{18}$ but their concentration obviously decreased with increasing $\mathrm{Bi}$ content. Although hillocks grew on these Sn- $x \mathrm{Bi}$ surfaces, no whiskers were observed after 100 thermal cycles. The maximum length/height of these hillocks or nodule features did not exceed $5 \mu \mathrm{m}$, while the length of the whiskers on the pure Sn surface reached approximately $30 \mu \mathrm{m}$ (Fig. 5a). The whisker mitigation effect by $\mathrm{Bi}$ addition is thus obvious in the case of severe thermal stress cycling.

In summary, we can conclude that small Bi addition can mitigate Sn whisker formation in four different environmental tests. As little as $0.5 \mathrm{wt} . \% \mathrm{Bi}$ addition exhibited an obvious mitigation effect, and 2.0 wt.\% addition was sufficient to avoid whiskers on the electroplating surface under ambient storage, at high humidity/temperature, under mechanical loading, or when exposed to thermal stress cycling.

\section{Microstructure of Sn- $x$ Bi Films Under Ambient Storage and Different IMC Growths}

The grain textures of the as-plated matte Sn and Sn- $x$ Bi films were investigated by FIB, as shown in Fig. 6. The average grain size decreased with increasing Bi content (Fig. 6a-d). The average grain size in the Sn-2Bi surface was approximately half
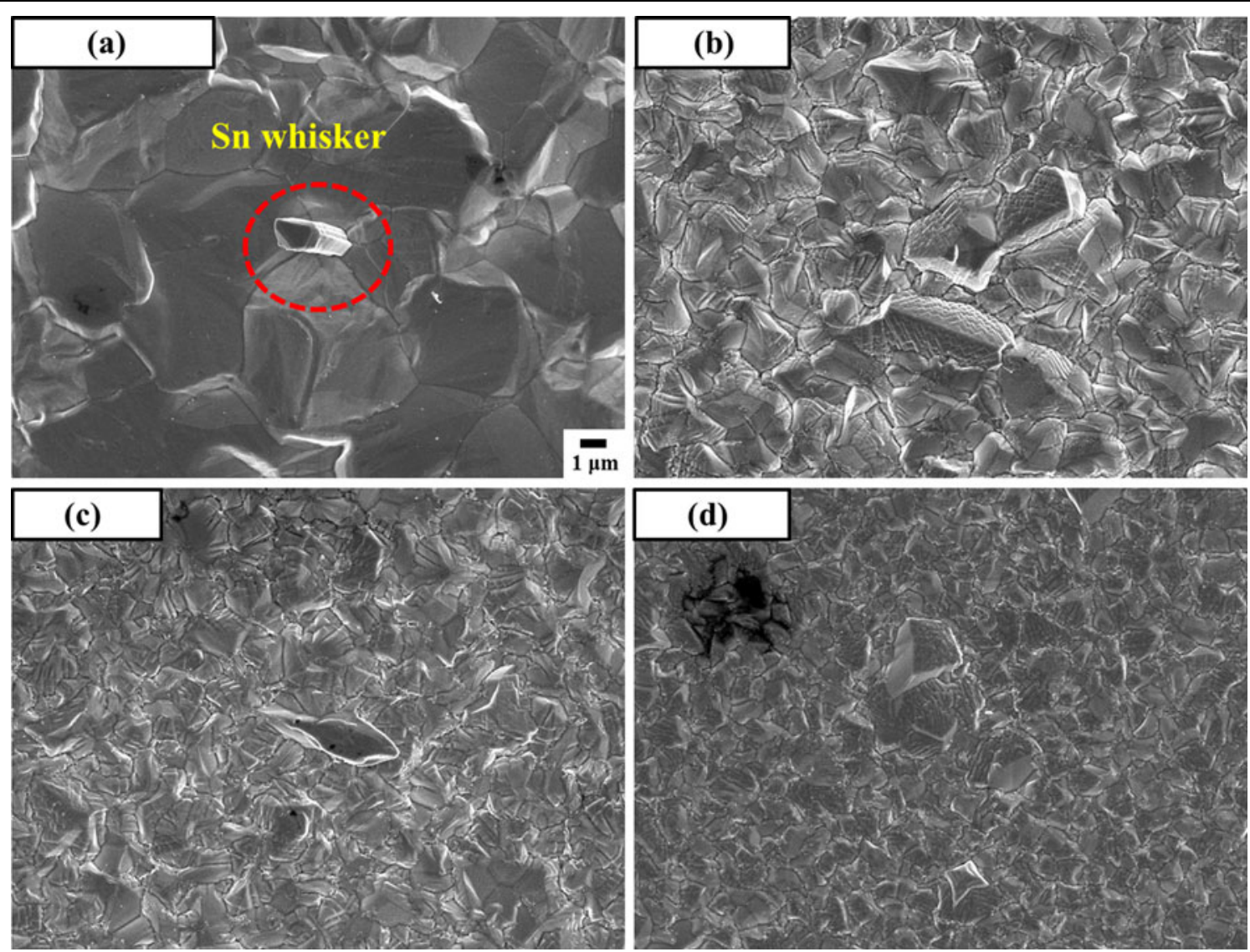

Fig. 3. Morphologies after $1000 \mathrm{~h}$ of high-humidity/temperature storage: (a) pure $\mathrm{Sn}$, (b) Sn-0.5Bi, (c) Sn-1Bi, and (d) Sn-2Bi. 
that in the pure Sn surface. Hence, small Bi addition, even $0.5 \mathrm{wt} \%$, to $\mathrm{Sn}$ refines the grain texture of the electroplated film.

Figure 7 compares the microstructure of the FIB cross-sections of Sn and Sn- $x \mathrm{Bi}$ : (a) as-plated and (b) after 1 year of ambient storage. The columnar grain structure in the pure Sn surface was altered to equiaxed grains with $\mathrm{Bi}$ addition. This equiaxed grain structure effectively relieved the compressive stress, thus mitigating Sn whisker formation. ${ }^{5}$ After 1 year of ambient-temperature storage, the $\mathrm{Sn}$ grains in the examined plated samples had increased in size, as shown in Fig. 7b. The columnar structure in the pure Sn surface remained unchanged during the 1-year storage, while the equiaxed grains in the $\mathrm{Sn}-x \mathrm{Bi}$ plating appeared to alter to columnar structure, probably because of GB movement caused by the observed grain expansion.

The IMC at the interface between the Sn film and $\mathrm{Cu}$ substrate continuously grew in the samples during the 1-year ambient-temperature storage, as confirmed by Fig. 7b. However, the growth patterns were different in the pure $\mathrm{Sn}$ and $\mathrm{Sn}-x \mathrm{Bi}$ surfaces. In the case of the pure Sn surface, IMC mainly grew along the Sn grain boundaries. In particular, large IMC growth could be observed at the boundaries around the root grain of the whisker on the pure $\mathrm{Sn}$ surface. Such growth induces compressive stress in the root grain and causes the whisker to grow to release the stress. In contrast, the volume of IMC grown in the $\mathrm{Sn}-x \mathrm{Bi}$ films after 1 year was smaller than in the pure $\mathrm{Sn}$ film, at both the $\mathrm{Sn} / \mathrm{Cu}$ interfaces and Sn grain boundaries. Moreover, the IMC in the $\mathrm{Sn}-x \mathrm{Bi}$ samples grew uniformly over the entire interface area during the storage tests. The cross-sectional observations shown in Fig. 7 indicate that room-temperature whiskers, which were found only on the pure Sn surface, were driven by concentrated IMC growth along grain boundaries. Doping with Bi resulted in a refined and equiaxed grain structure due to partial and frequent crystal nucleation during electroplating. The refined grains provided additional diffusion paths at the interface between the $\mathrm{Sn}$ and the $\mathrm{Cu}$ substrate,${ }^{19}$ avoiding the IMC growth concentrated on the grain boundaries.

The hillocks observed on all the Sn-xBi surfaces are considered to relieve the compressive stress accumulated during storage. These hillocks mainly occur from GB migration. ${ }^{5,11}$ Figure 8 shows a typical hillock on a Sn-0.5Bi surface: (a) surface top view, (b) cross-sectional view, and (c) magnified image of cross-section. The considerably uniform IMC growth under the hillock assists Sn GB migration and allows grain growth to form the hillock. The hillock growth effectively releases the compressive stress without growth of whiskers during ambient storage. The small Bi addition used in our study eliminates whisker formation during 1 year of ambient storage by changing the IMC growth pattern from being concentrated at grain boundaries to being uniformly distributed at the plating/substrate interface.
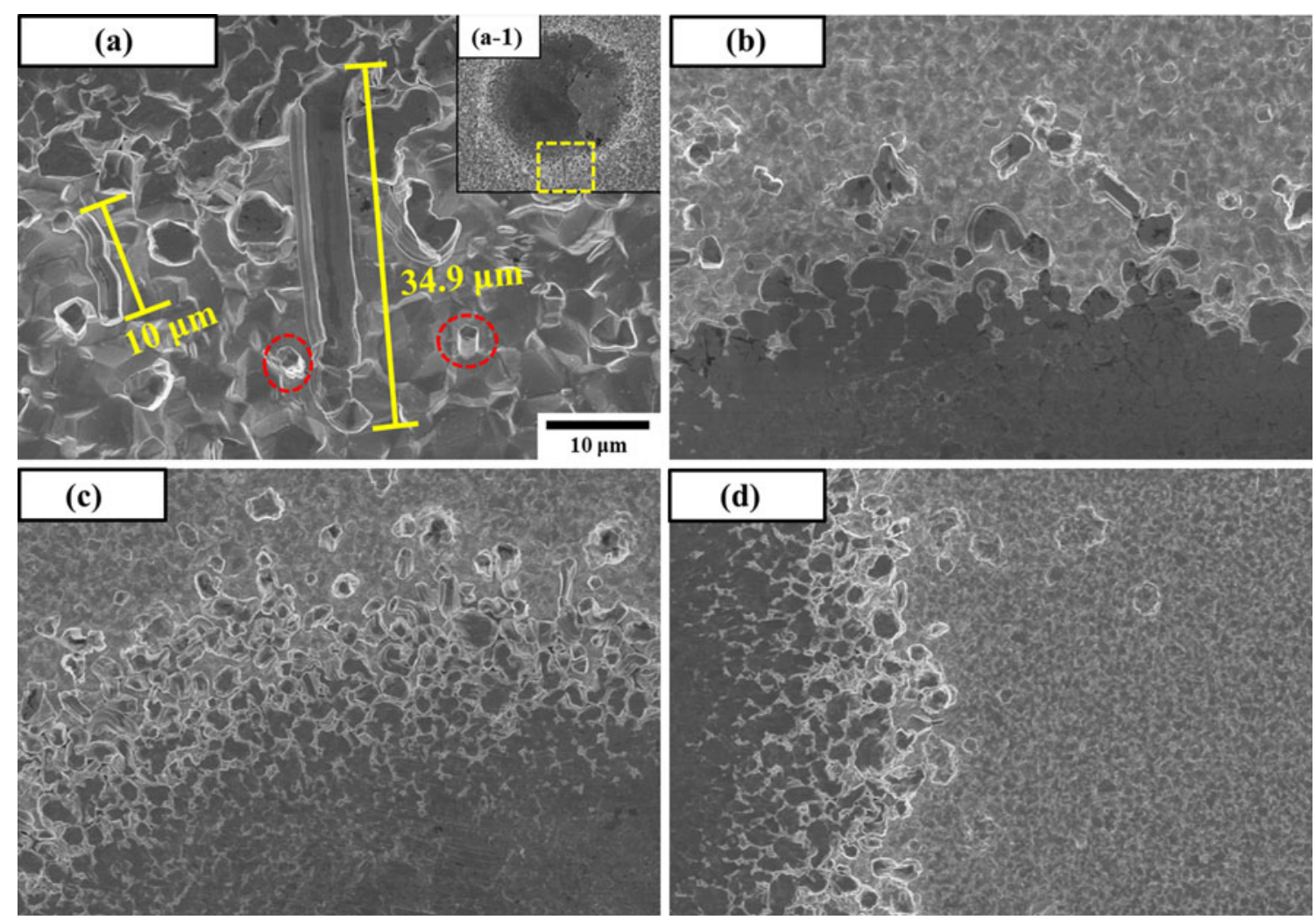

Fig. 4. Morphologies after 72-h loading tests: (a) pure Sn, (b) Sn-0.5Bi, (c) Sn-1Bi, and (d) Sn-2Bi. 

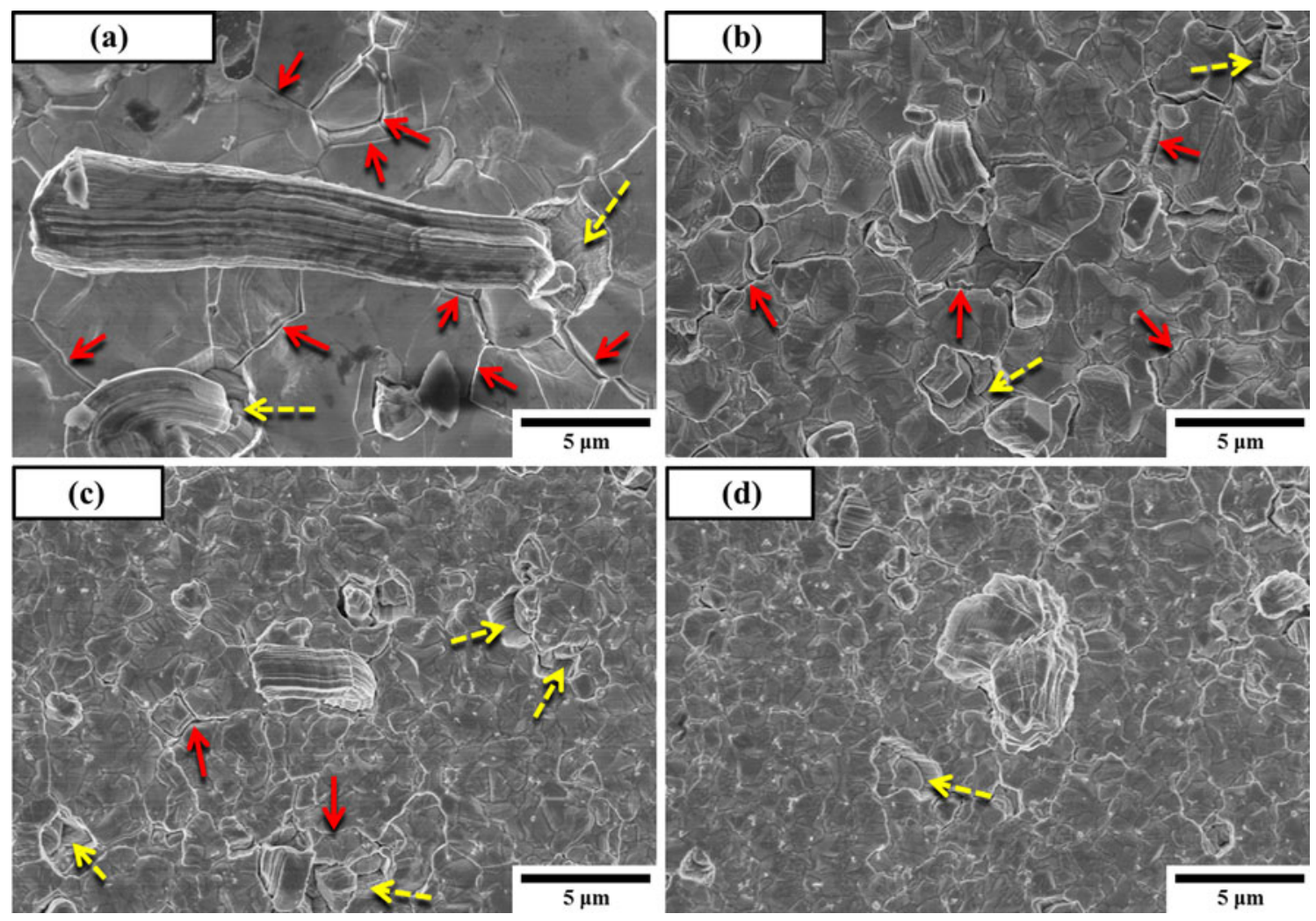

Fig. 5. Morphologies after 100 thermal cycles: (a) pure $\mathrm{Sn}$, (b) Sn-0.5Bi, (c) Sn-1Bi, and (d) Sn-2Bi.
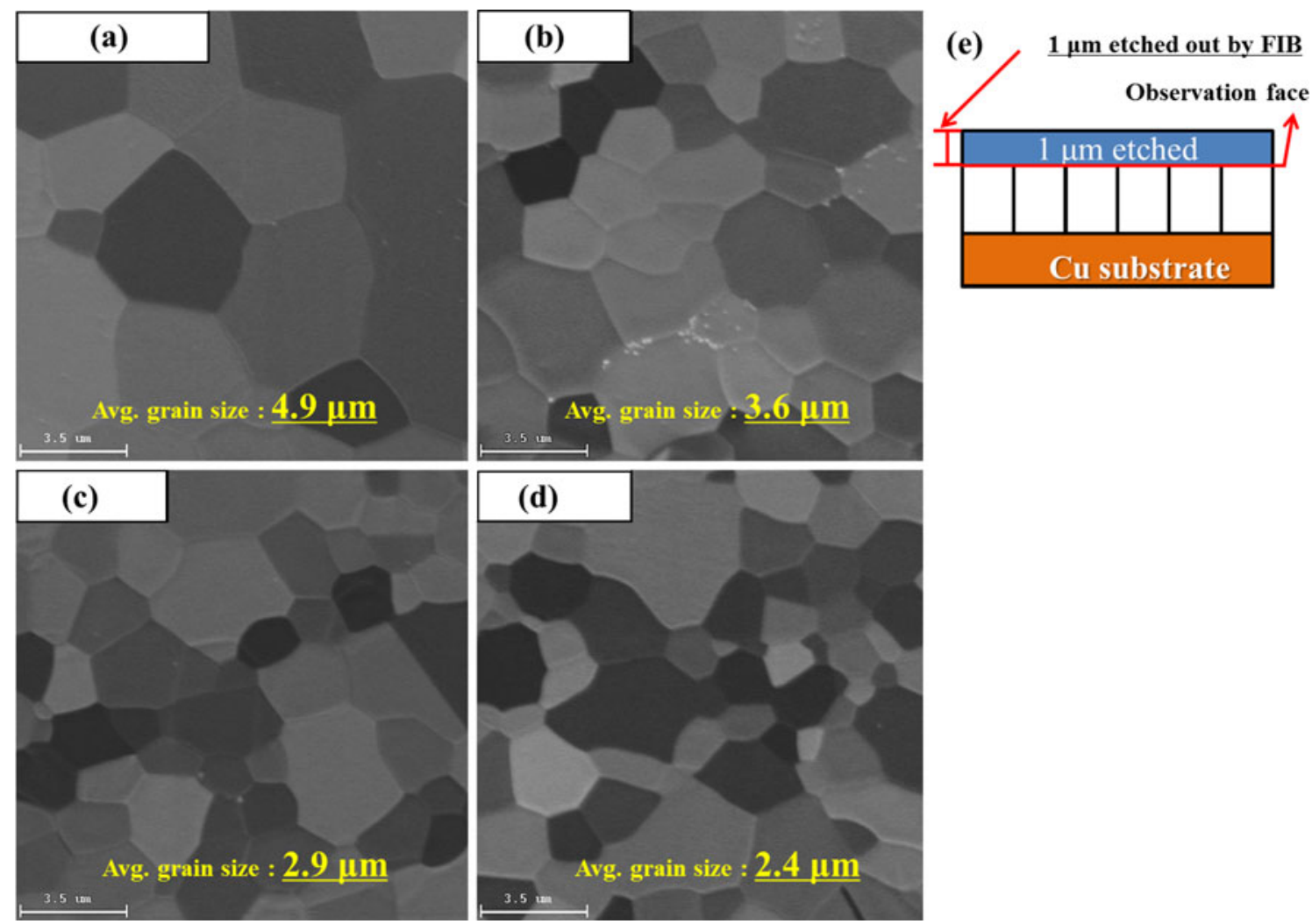

Fig. 6. Grain size observations of as-plated films using FIB microscopy: (a) pure Sn, (b) Sn-0.5Bi, (c) Sn-1Bi, and (d) Sn-2Bi; (e) schematic diagram of FIB etching. 
(a)
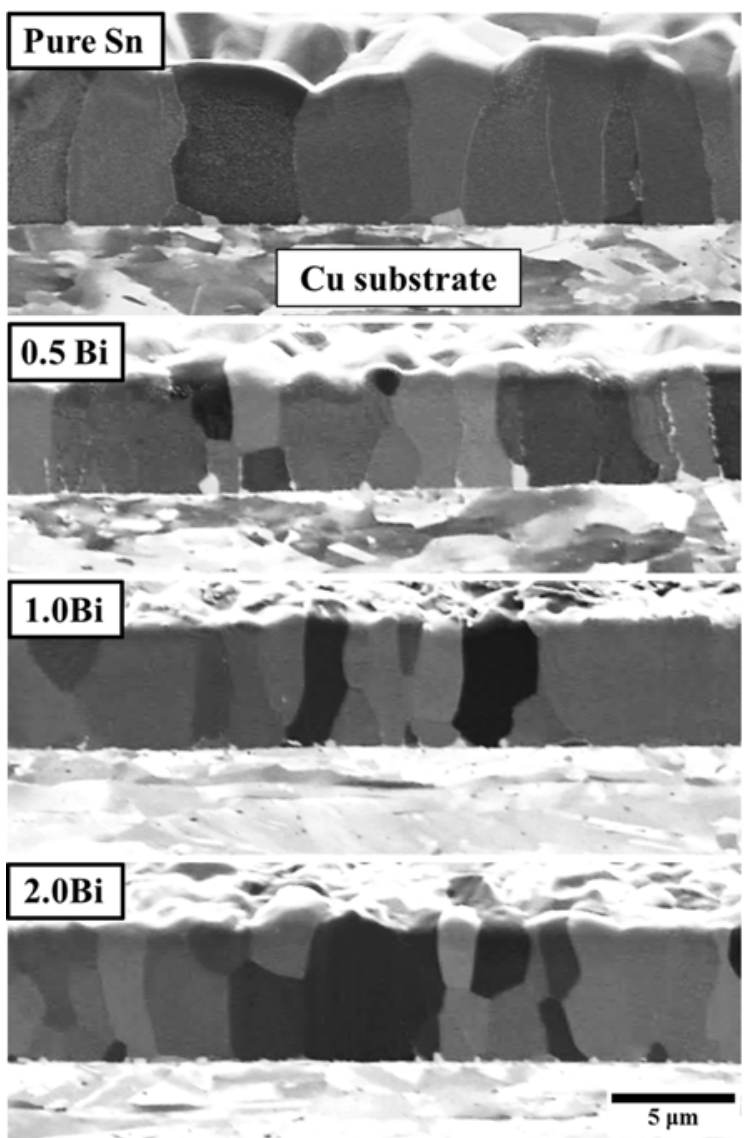

(b)
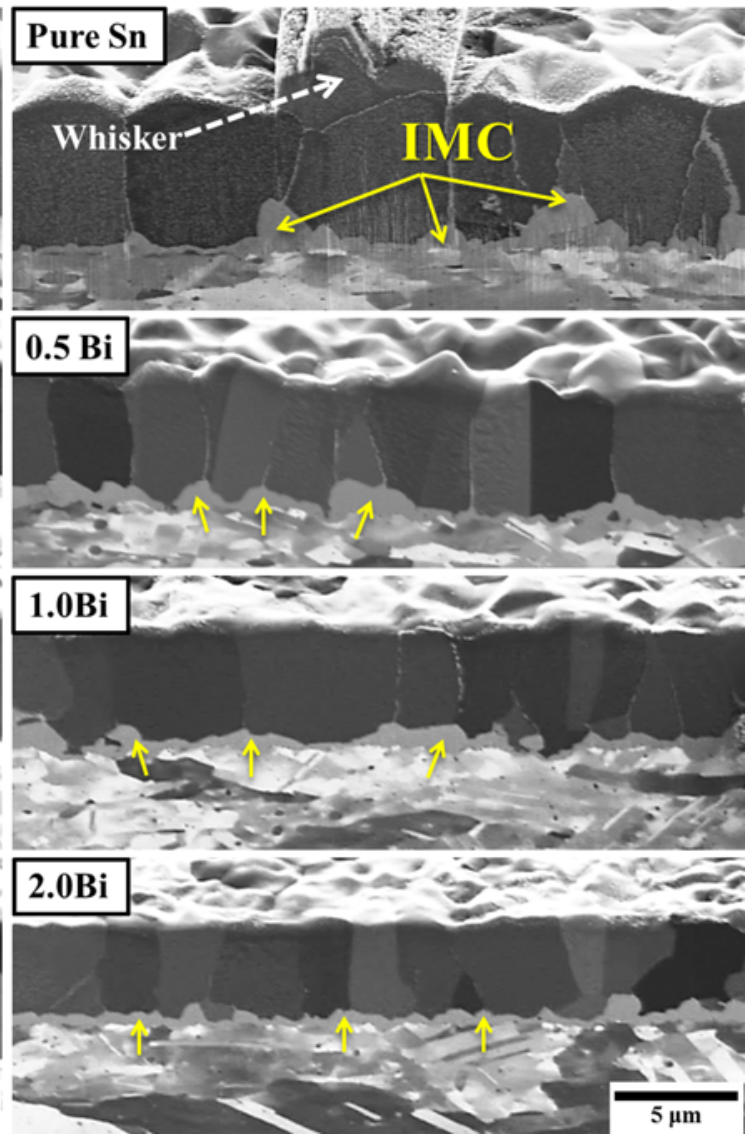

Fig. 7. Cross-sectional views of pure $\mathrm{Sn}$ and $\mathrm{Sn}-x \mathrm{Bi}$ plating: (a) as-plated and (b) after 1 year of ambient storage.
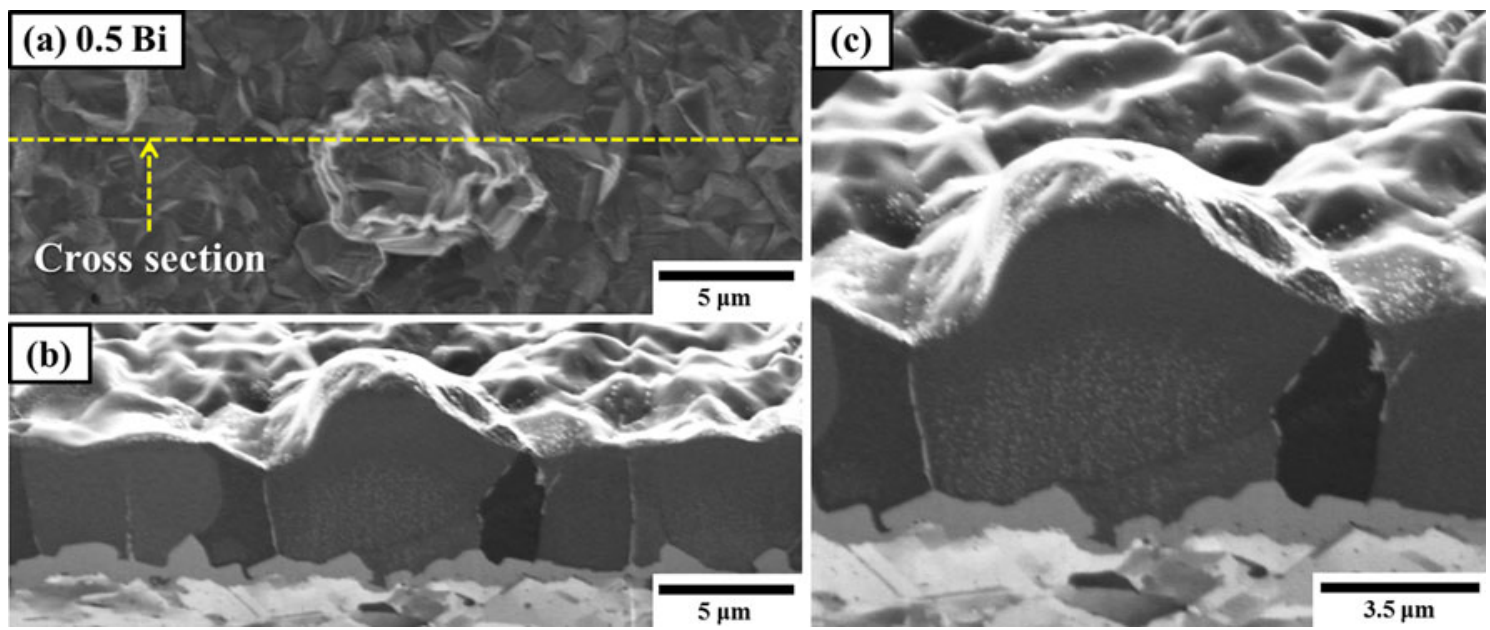

Fig. 8. Hillock observed on Sn-0.5Bi plating after 1 year of ambient storage: (a) top view of the hillock, (b) cross-sectional observation, and (c) magnified image of the grain microstructure.

\section{The Whisker Mitigation Mechanism by Least Bi Addition}

Sn whisker growth, in general, is caused to relieve stresses accumulated in the film. In our study, four different types of loading were investigated to create stress inside the electroplated films. During room-temperature storage, compressive internal stress is generated by grain expansion and IMC growth. External loading supplied by directional indentation and CTE mismatch during thermal cycling resulted in accumulated compressive stress 
in and on the Sn layer. The compressive stress is effectively relieved by a small amount of $\mathrm{Bi}$ addition that alters the columnar $\mathrm{Sn}$ grains to equiaxed structure. The IMC growth pattern is also changed to a uniform distribution at the interface between the substrate and plated $\mathrm{Sn}$ layer. These effects of $\mathrm{Bi}$ doping are similar to those caused by $\mathrm{Pb}$ addition on IMC growth. ${ }^{11}$ When $\mathrm{Sn}$ is alloyed with $\mathrm{Pb}$, segregated $\mathrm{Pb}$ at $\mathrm{Sn}$ grain boundaries blocks GB IMC growth, while segregated $\mathrm{Bi}$ was not observed in the present study. The whisker mitigation mechanism by Bi doping is thus mainly related to the altered grain structure, i.e., columnar to equiaxed, due to the grain refinement. The refined, equiaxed grain structure is superior to relieve compressive stress in any of our four environmental test cases. Particularly in thermal cycling, the refined grain structure suppressed surface oxidation cracking along grain boundaries, which is relevant to reduce whisker density. ${ }^{20}$ It is remarkable that the obvious whisker mitigation effect starts from $0.5 \mathrm{wt} . \%$ of $\mathrm{Bi}$ addition even in thin plating films of $5 \mu \mathrm{m}$ thickness.

\section{CONCLUSIONS}

In this study, Sn whisker mitigation by small Bi addition was investigated by comparing pure matte $\mathrm{Sn}$ and Sn- $x$ Bi electroplated films of $5 \mu \mathrm{m}$ thickness on either $\mathrm{Cu}$ or 42 alloy substrates using four different environmental tests. Sn whiskers were observed only on pure Sn surfaces; no whiskers (only some extrusions/hillocks) were observed on the alloyed films during 1-year ambient-temperature storage, HTH, loading, and thermal cycling tests. In these tests, whisker growth was efficiently suppressed by $\mathrm{Bi}$ addition as low as 0.5 wt.\%, which refined the grain size and altered the grain structure from columnar to equiaxed. Small amounts of $\mathrm{Bi}$ addition mitigated Sn whisker formation by suppressing IMC growth at Sn grain boundaries, allowing GB migration, and resulting in hillock growth that could release the compressive stress during ambient storage. Our results nevertheless agree with a previous report on thermal cycling with higher $\mathrm{Bi}$ addition (2.5 wt.\%). ${ }^{12}$ We further conclude that the minimum requirement of $\mathrm{Bi}$ addition necessary for whisker mitigation can be $\leq 0.5$ wt.\%. Further elucidation of the mechanisms of whisker mitigation found in $\mathrm{Sn}-x \mathrm{Bi}$ electroplating would guide additional investigations on metal whisker suppression, in addition to realizing the whisker-free $\mathrm{Sn}$ plating required for $\mathrm{Pb}$-free electronic devices.

\section{ACKNOWLEDGEMENTS}

This work was partially supported by Grant-inAid for Scientific Research (S) Grant Number 24226017.

\section{REFERENCES}

1. K.J. Puttlitz and G.T. Galyon, J. Mater. Sci.: Mater. Electron. 18, 347 (2007).

2. H.P. Howard, J. Cheng, P.T. Vianco, and J.C.M. Li, Acta Mater. 59, 1957 (2011).

3. K.G. Comptom, A. Mendizza, and S.M. Arnold, Corrosion 7, 327 (1951).

4. H.L. Cobb, Mon. Rev. Am. Electroplat. Soc. 33, 28 (1946).

5. W.J. Boettinger, C.E. Johnson, L.A. Bendersky, K.-W. Moon, M.E. Williams, and G.R. Stafford, Acta Mater. 53, 5033 (2005).

6. K.N. Tu and J.C.M. Li, Mater. Sci. Eng. A 409, 131 (2005).

7. J.W. Osenbach, R.L. Shook, B.T. Vaccaro, B.D. Potteiger, A.N. Amin, K.N. Hooghan, P. Suratkar, and P. Ruengsinsub, IEEE Trans. Electron. Packag. Manuf. 28, 36 (2005).

8. M.-H. Lu and K.-C. Hsieh, J. Electron. Mater. 36, 1448 (2007).

9. E. Chason, N. Jadhav, and F. Pei, JOM 63, 62 (2011).

10. J. Cheng, F. Yang, P.T. Vianco, B. Zhang, and J.C.M. Li, J. Electron. Mater. 40, 2069 (2011).

11. J-L. Jo, K-S. Kim, T. Sugahara, S. Nagao, K. Hamasaki, M. Tsujimoto, and K. Suganuma, J. Mater. Sci. Mater. Electron. (2013). doi:10.1007/s10854-013-1218-y.

12. N. Jadhav, M. Williams, F. Pei, G. Stafford, and E. Chason, J. Electron. Mater. 42, 312 (2013).

13. J. Huaa, Y. Zhang, and C. Wub, J. Mater. Process. Technol. 211, 463 (2011).

14. H.S. Betrabet, S.M. McGee, and J.K. McKinlay, Scripta Mater. 25, 2323 (1991).

15. B. Horváth, B. Illés, T. Shinohara, and G. Harsányi, Thin Solid Films 520, 384 (2011).

16. P. Oberndorff, M. Dittes, P. Crema, P. Su, and E. Yu, IEEE Trans. Electron. Packag. Manuf. 29, 239 (2006).

17. C.-F. Li, Z.-Q. Liu, and J.-K. Shang, J. Alloys Compd. 550, 231 (2013)

18. K. Suganuma, A. Baated, K.-S. Kim, K. Hamasaki, N. Nemoto, T. Nakagawa, and T. Yamada, Acta Mater. 59, 7255 (2011).

19. E. Sandnes, M.E. Williams, M.D. Vaudin, and G.R. Stafford, J. Electron. Mater. 37, 490 (2008).

20. J-L. Jo, S. Nagao, T. Sugahara, M. Tsujimoto, and K. Suganuma, J. Mater. Sci. Mater. Electron. (2013). doi: 10.1007/s10854-013-1336-6. 